\title{
Development of learning professionalism assessment battery for medical residents
}

\author{
SEYED KAMRAN SOLTANI ARABSHAHI ${ }^{1}$, MARYAM AKBARILAKEH ${ }^{2 *}$, HOORIEH MOHAMMADI KENARI ${ }^{3}$, MOHAMED \\ ELHASSAN ABDALLA ${ }^{4}$ \\ ${ }^{1}$ Professor of Medical Education, Center for Educational Research in Medical Sciences, School of Medicine, Iran University of Medical \\ Sciences, Tehran, Iran. \\ ${ }^{2}$ Assistant Professor of Medical Education, Department of Medical Education, Center for Educational Research in Medical Sciences \\ (CERMS), School of Medicine, Iran University of Medical Sciences, Tehran, Iran. \\ ${ }^{3}$ Assistant professor of Persian Medicine, Department of Persian Medicine, Research Institute for Islamic and Complementary Medicine, \\ School of Persian Medicine, Iran University of Medical Sciences, Tehran, Iran. \\ ${ }^{4}$ Assistant Professor Of Medical Education, Senior lecturer in Medical Education, University of Limerick, Ireland. \\ Corresponding author Email: \{akbari_maryam59@yahoo.com\} Telephone number: 0098-9356983533
}

\begin{abstract}
Background: Professionalism is an exit learning outcome of health professions' curricula. Much work has focused on professionalism teaching and little on the ways assessing it. The main goal was to develop composite assessment instrument as a battery accurately measured several aspects of learning professionalism in medical residents.

Methods: The first step in battery development was to decide on the domains to be addressed. Based on the comprehensive review of the literature, a list of domains to assess was developed and identified specific assessment instruments for each domain. Based on the instrument selection criteria, forty one Assessment instruments were selected and developed to comprise the assessment battery.

Results: The results are presented in 6 Section tests: duration, cost of each section, administration instruction, and scoring. The time required to complete the entire assessment battery was 100 minutes on average.

Conclusions: The resulting battery was developed by selecting a set of validated assessment instruments and combining them into a battery. The assessment battery is easy to administer, easy for residents to complete, and provides a comprehensive assessment of a residents' learning professionalism for teachers.

Keywords: professionalism, learning, assessment, battery, residents
\end{abstract}

\section{INTRODUCTION}

Professionalism is an employee characteristic which refers to ability to hold professional standards and to maintain the professional competence to be expected. A professional is someone who has completed formal education and training knowledge and skills necessary to perform the role of that profession. In addition, professionals are subject to codes of ethical and moral conduct. Professional standards of practice and ethics for a particular field are typically agreed upon and maintained through widely recognized professional associations ${ }^{1}$.

Residency is postgraduate training in medical education. It refers to who practices medicine in a clinical setting under the direct or indirect supervision of a senior medical clinician in a specialty such as Pediatrics, Radiology, Dermatology, Internal medicine, Surgery, Ophthalmology and etc ${ }^{2}$.

Professionalism is an exit learning outcome of health professions' curricula ${ }^{3}$. Professionalism key attributes should be learnt during the curriculum ${ }^{4}$. Health professions' teacher can use various teaching and learning methods for professionalism such as role modeling to promote it 5 . Various types of assessing methods of professionalism can use Identifying learning professionalism deficiencies ${ }^{6}$. There is variety of tools for assessing learning professionalism, each of which assesses one aspect of professionalism ${ }^{7}$.

There are various Structured, standardized and effective measures for measuring residents' professionalism which developed during the past decade such as rating scales, direct observation, multi-source feedback, and etc ${ }^{8}$.

If all dimensions of professionalism be considered in teaching professionalism, learning manifestation seen in professional behavior. The assessment battery is a composite instrument helps to identify declines in professionalism learning ${ }^{9}$. The main goal of this study was to develop composite assessment instrument as a comprehensive battery of professionalism assessment accurately measured several aspects of learning professionalism in medical residents.

\section{MATERIALS AND METHODS}

Development of Assessment Battery: The first step in battery development was to decide on the assessment domains and areas to be addressed(10). Based on the comprehensive review of the literature, a list of domains and areas within the domains to assess was developed. Through the search of the electronic databases until 2020, was administered to identify studies assessing learning professionalism in medical residents. Search strategy included a combination of the five aspects including construct, population, instrument, and measurement properties, exclusion filter, developed(11). Some of the instruments assesses professionalism as a facet of competence; some others assessing professionalism as a comprehensive construct; and the others instruments separate elements of professionalism, such as humanism and empathy ${ }^{12,13}$. This study included all instruments which used assessing learning professionalism to develop a 
comprehensive assessment battery for medical residents. Screening the titles and abstracts of the included full texts for target population was residents and considering full texts which described the measurement properties of the instrument as shown in the following table.

Table 1: Professionalism domains and related assessment instruments

Domains/ assessment area

Excellence; Honor/integrity; Altruism/respect; Accountability to Patients, Society and the Profession; Commitment to Ethical Principles; Responsiveness to the Needs of Patients and Society that Supersedes Self -interest; Commitment to Excellence and Ongoing Professional Development; Demonstrate Respect, Compassion, and Integrity; Demonstrate Sensitivity and Responsiveness to Patients; Empathy; Interpersonal relationships with patients; Conveying medical information to patients;

Punctuality; Appearance; Honesty/accountability/response to error; Compulsiveness; Responsibility/sense of duty Response to criticism; Confidence/ability to assess oneself; Respect for others; Initiative/self-regulation; Altruism; Doctor-patient or doctor-family relationships; Inter-professional relationships; Trustworthiness/confidentiality; Moral and ethical standards; Attitude toward medical profession; Doctor-patient relationship skills; Reflective skills; Time management; Inter-professional relationship skills; Integrity; Detachment and commitment; Respect; Trans mural care; Cooperation with specialists; Cooperation with support personnel; Accountability; Ability to make use of the opportunities of the profession; Norms and values; Self-reflection; Self-confidence; Self-welfare; Deal with patient diversity; Leadership; Collegiality; Quality management; Practice management; Provide and receive feedback; Life-long learning; Resilience; Dealing with mistakes; Dealing with uncertainty; Cope with aggression; Respecting patient's interests; Professional distance; Collaboration skills; Management skills; Responsibility; Quality management; Reflection and learning; Dealing with emotions; Courteousness and respect in interaction with patients; Communication with patients; Collaboration with patients and colleagues; Dedication and sense of responsibility; Knowing one's own limits and receptiveness for feedback; Altruism, trust, and patient interest; Patient autonomy; Social justice; Responsibility to patients; Respect for patients

Altruism, trust, and patient interest; Patient autonomy; Social justice; Responsibility to patients; Respect for patients

Altruism, trust, and patient interest; Patient autonomy; Social justice; Responsibility to patients; Respect for patients

Listening; trustworthiness; answering directly; respect;

Accountability to Patients, Society and the Profession; Commitment to Ethical Principles; Commitment to

Excellence and Ongoing Professional Development; Demonstrate Respect, Compassion, and Integrity

\begin{tabular}{|l|l|}
\hline Type of instrument & Citation \\
\hline Self-administrated rating & $(14)$ \\
& $(15)$ \\
& $(16)$ \\
& $(17)$ \\
& $(18)$ \\
$(19)$ \\
\hline Direct observation & $(20)$ \\
& $(21)$ \\
& $(22)$ \\
& $(23)$ \\
& $(24)$ \\
& $(13)$ \\
& \\
& \\
& \\
\hline simulation & \\
& \\
\hline Multi Source Feedback & $(13)$ \\
\hline Role model evaluation & $(17)$ \\
\hline professionalism environment & $(17)$ \\
& \\
\hline
\end{tabular}

Table 2: Names of forty one assessment instruments used in the battery

\begin{tabular}{|c|c|c|}
\hline Test No & Name & Citation \\
\hline 1 & Arnold scale-14 items - self-administered rating & $(12) 12$ \\
\hline 2 & Arnold scale-12 items- self-administered rating & (15) 15 \\
\hline 3 & Arnold scale-17 items- self-administered rating & $(16) 16$ \\
\hline 4 & Gillespie's scale - self-administered rating & (17) 17 \\
\hline 5 & Hotjat's Jefferson competency scale- self-administered rating & $(18) 18$ \\
\hline 6 & ABIM Patient Assessment-self assessment version- Self-administrated rating & (19) 19 \\
\hline 7 & UMDSPAI - direct observation & $(20) 20$ \\
\hline 8 & P-MEX- direct observation & $(21) 21$ \\
\hline 9 & EPRO-GP instrument - direct observation & $(22) 22$ \\
\hline 10 & Nijmegen Professionalism Scale - direct observation & (23) 23 \\
\hline 11 & Adaptation of AACS for foreigner - direct observation & $(24) 24$ \\
\hline 12 & p-mini-CEX - direct observation & (13) 13 \\
\hline 13 & ACGME-TRF- Direct observation & (25) 25 \\
\hline 14 & Global rating form for ACGME competencies- Direct observation & (26) 26 \\
\hline 15 & OCEX- Direct observation & $(27)(28)$ \\
\hline 16 & ACGME general competencies- Direct observation & (29) 29 \\
\hline 17 & Durning's Supervisor's evaluation form- Direct observation & $(30) 30$ \\
\hline 18 & Durning's Supervisor's evaluation form-PGY3- Direct observation & $((31) 31$ \\
\hline 19 & COMPASS- Direct observation & $(23)$ \\
\hline 20 & ITER- Direct observation & $\frac{(20)}{(32)}$ \\
\hline 21 & Dong's Graduates Form- Direct observation & $(33)$ \\
\hline 22 & ECFMG-CSA-simulation & $(34) 34$ \\
\hline 23 & $\mathrm{p}$-OSCE-simulation & $(35) 35$ \\
\hline 24 & SDOT- Simulation & $(36) 36$ \\
\hline 25 & Jefferies's OSCE of CanMEDS Roles- Simulation & $(37) 27$ \\
\hline 26 & Ponton-Carss Checklist of OSPRE- Simulation & $(38) 38$ \\
\hline 27 & RO\&CA- Simulation & $(39) 39$ \\
\hline 28 & ACGME competency checklist of OSCE- Simulation & $(40) 40$ \\
\hline 29 & CanMEDS OSCE- Simulation & $(13) 13$ \\
\hline 30 & p- $360^{\circ}$ evaluation -multi source feedback & (35) 35 \\
\hline 31 & Musick 360-degree instrument- Multi Source Feedback & (41) 41 \\
\hline 32 & Wood's 360-degree evaluation- Multi Source Feedback & $(42) 42$ \\
\hline 33 & End-of-rotation evaluations- Multi Source Feedback & $(43) 43$ \\
\hline 34 & EOS group 360-degree instrument -Multi Source Feedback & $(44)(44)$ \\
\hline 35 & Senol's Turkish 360-degree assessment- Multi Source Feedback & $(45) 45$ \\
\hline 36 & CPSA-PAR MSF for international graduates- Multi Source Feedback & $\frac{1+4)}{(46)} 46$ \\
\hline 37 & Ephgrave's Assessment -Role model evaluation & (47) 47 \\
\hline 38 & Faculty Supervision Evaluation- Role model evaluation & (48) 48 \\
\hline 39 & Colletti evaluation of clinical educators- Role model evaluation & (49) 49 \\
\hline 40 & Smith instrument- Role model evaluation & $(50) 50$ \\
\hline 41 & Gillespie's scale- professionalism environment & $(17) 17$ \\
\hline
\end{tabular}

The literature search was also conducted to identify specific assessment instruments for each area. The list of instruments was organized by the assessment domain and the function assessed. To select instruments for the 
assessment battery the criteria were used: such as easy and quick to administer, low cost, presence of reliability and validity data, specific for a residents. Based on these criteria 41 Assessment instruments were selected and developed to comprise the assessment battery. Details about each section of battery including the required materials, the area(s) they were designed to assess, administration instructions, scoring instructions, and references are included in our assessment Battery.

Subjects of study: Subjects and target population of this battery are medical residents of internal medicine, psychiatry, emergency medicine, pediatrics, surgery, medicine Primary care, obstetrics, gynecology, general practice, neurology, ophthalmology, Radiology, dermatology, anesthesia.

\section{RESULTS}

The results are presented in 6 Section tests: duration, cost of each section, administration instruction, and scoring. The time required to complete the entire assessment battery was 100 minutes on average. Note that some of the tests require special equipment and the other instruments can be administered from common office materials or reproduced without a fee.

Table 3: Time required completing the entire assessment battery and costs

\begin{tabular}{|l|l|l|}
\hline Test name & Time & Cost \\
\hline self-administered rating & $20 \mathrm{~min}$ & $\$ 20$ \\
\hline direct observation & $30 \mathrm{~min}$ & $\$ 30$ \\
\hline simulation & $15 \mathrm{~min}$ & $\$ 15$ \\
\hline multi source feedback & $15 \mathrm{~min}$ & $\$ 15$ \\
\hline Role model evaluation & $10 \mathrm{~min}$ & $\$ 10$ \\
\hline professionalism environment & $10 \mathrm{~min}$ & $\$ 10$ \\
\hline Assessment battery & 100 minutes & $\mathbf{\$ 1 0 0}$ \\
\hline
\end{tabular}

\section{DISCUSSION}

The resulting battery was developed by selecting a set of validated assessment instruments and combining them into a battery, whose total cost for acquisition was $\$ 100$. As part of this battery, six tests were developed utilizing items from established validated questionnaires and measures with minor modifications. The study found that the assessment battery required on average less than 100 minutes completing. In conclusion, the assessment battery developed by this study, is easy to administer, easy for residents to complete, and provides a comprehensive assessment of a residents' learning professionalism for teachers. We believe that the assessment battery would serve as a valuable data collection tool for a longitudinal study of learning professionalism in medical graduates.

Testing of the battery entailed administrating the battery to a convenience sample of residents is proposed. The battery should be conducted a process evaluation of the battery to ensure that it was acceptable to teachers and learners; obtained high data-quality; and was easily administered. The time required to complete various sections of the battery should be measured. Feedback about the battery should be gathered from all residents and the battery administrator. In general, residents' comments should be gathered about the battery. The test administrator comments should be gathered about the ease of administering each of the tests, all the comments help us to do modifications about the battery, remove some sections from the assessment battery and or add any extra required features to it. The assessment battery developed by this study, is easy to administer, easy for residents to complete, and provides a comprehensive assessment of a residents' learning professionalism for teachers.

Ethics approval and consent to participate: All methods were carried out in accordance with relevant guidelines and regulations. All protocols were approved by Ethics Committee in Biomedical Research of Iran University of Medical Sciences (IR.IUMS.REC.1400.).

Consent for publication: Not applicable.

Availability of data and materials: The datasets used and/or analyzed during the current study are available from the corresponding authors on reasonable request.

Conflict of interest: The authors declare that there is no conflict of interest.

Funding: Self-funded.

Authors' contributions: Soltani Arabshahi S.A. was involved in planning and supervised the work, Akbarilakeh M. processed and performed the review, analysis, drafted the manuscript and designed the battery. Mohammadi Kenari $H$. Involved in review, analysis, drafted the manuscript. Abdalla M.E involved in review, analysis, drafted the manuscript. They wrote the manuscript with scientific support and helped supervise the project Akbarilakeh $\mathrm{M}$. involved in interpreting the results, worked on the manuscript and edited it. All authors discussed the results and commented on the manuscript. All authors read the final copy of manuscript and confirmed it for submission.

Acknowledgments: This article is the result of a research project with assigned number 0-1-35-20763, which was approved in Center for Educational Research in Medical Sciences (CERMS), Iran University of Medical Sciences.

\section{REFERENCES}

1. Donnelly B. Work and Integrity: The Crisis and Promise of Professionalism in America. World Futures. 2008;64(3):222-5.

2. De Pietro C, Camenzind P, Sturny I, Crivelli L, Edwards-Garavoglia S, Spranger A, et al. Switzerland: Health System Review. Health systems in transition. 2015;17(4):1-288, xix.

3. Stern DT, Papadakis M. The developing physician--becoming a professional. The New England journal of medicine. 2006;355(17):1794-9.

4. Swing SR. The ACGME outcome project: retrospective and prospective. Medical teacher. 2007;29(7):648-54.

5. Goldie J, Dowie A, Cotton P, Morrison J. Teaching professionalism in the early years of a medical curriculum: a qualitative study. Medical education. 2007;41(6):610-7.

6. Shrank WH, Reed VA, Jernstedt GC. Fostering professionalism in medical education: a call for improved assessment and meaningful incentives. J Gen Intern Med. 2004:19(8):887-92.

7. Ferguson RP. Professionalism: hard to measure but you know it when you see it. J Community Hosp Intern Med Perspect. 2014;4(2):10.3402/jchimp.v4.24226

8. Veloski JJ, Fields SK, Boex JR, Blank LL. Measuring professionalism: a review of studies with instruments reported in the literature between 1982 and 2002. Academic medicine : journal of the Association of American Medical Colleges. 2005;80(4):366-70.

9. Wesman AG. A TEST BATTERY FOR TEACHING TESTS AND MEASUREMENTS. The Yearbook of the National Council on Measurements Used in Education. 1956(13):76-8.

10. Coxhead P, Gupta RM. Construction of a Test Battery to Measure Learning Potential. In: Gupta RM, Coxhead P, editors. Cultural Diversity and Learning Efficiency: Recent Developments in Assessment. London: Palgrave Macmillan UK; 1988. p. 118-40. 
11. Terwee CB, Jansma EP, Riphagen II, de Vet HCW. Development of a methodological PubMed search filter for finding studies on measurement properties of measurement instruments. Quality of Life Research. 2009;18(8):1115-23.

12. Arnold L. Assessing professional behavior: yesterday, today, and tomorrow. Academic medicine : journal of the Association of American Medical Colleges. 2002;77(6):502-15.

13. Li H, Ding $N$, Zhang $Y$, Liu $Y$, Wen D. Assessing medical professionalism: A systematic review of instruments and their measurement properties. PloS one. 2017;12(5):e0177321.

14. Arnold EL, Blank LL, Race KE, Cipparrone N. Can professionalism be measured? The development of a scale for use in the medical environment. Academic medicine : journal of the Association of American Medical Colleges. 1998;73(10):1119-21.

15. DeLisa JA, Foye PM, Jain SS, Kirshblum S, Christodoulou C Measuring professionalism in a physiatry residency training program. American journal of physical medicine \& rehabilitation. $2001 ; 80(3): 225-9$.

16. Aramesh K, Mohebbi M, Jessri M, Sanagou M. Measuring professionalism in residency training programs in Iran. Medica teacher. 2009;31(8):e356-61.

17. Gillespie C, Paik S, Ark T, Zabar S, Kalet A. Residents' perceptions of their own professionalism and the professionalism of their learning environment. J Grad Med Educ. 2009;1(2):208-15.

18. Hojat M, Paskin DL, Callahan CA, Nasca TJ, Louis DZ, Veloski J, et al. Components of postgraduate competence: analyses of thirty years of longitudinal data. Medical education. 2007;41(10):982-9.

19. Symons AB, Swanson A, McGuigan D, Orrange S, AkI EA. A tool for self-assessment of communication skills and professionalism in residents. BMC medical education. 2009;9:1.

20. Gauger PG, Gruppen LD, Minter RM, Colletti LM, Stern DT. Initial use of a novel instrument to measure professionalism in surgical residents. American journal of surgery. 2005;189(4):479-87.

21. Cruess R, Mcllroy JH, Cruess S, Ginsburg S, Steinert Y. The Professionalism Mini-evaluation Exercise: a preliminary investigation. Academic medicine : journal of the Association of American Medical Colleges. 2006;81(10 Suppl):S74-8.

22. van de Camp K, Vernooij-Dassen M, Grol R, Bottema B Professionalism in general practice: development of an instrument to assess professional behaviour in general practitioner trainees. Medical education. 2006;40(1):43-50.

23. Tromp F, Vernooij-Dassen M, Kramer A, Grol R, Bottema B Behavioural elements of professionalism: assessment of a fundamental concept in medical care. Medical teacher 2010;32(4):e161-9

24. Vermeulen MI, Tromp F, Zuithoff NPA, Pieters RHM, Damoiseaux RAMJ, Kuyvenhoven MM. A competency based selection procedure for Dutch postgraduate GP training: A pilot study on validity and reliability. European Journal of General Practice. 2014;20(4):307-13.

25. Abu Dabrh AM, Waller TA, Bonacci RP, Nawaz AJ, Keith JJ, Agarwal $A$, et al. Professionalism and inter-communication skills (ICS): a multi-site validity study assessing proficiency in core competencies and milestones in medical learners. BMC medical education. 2020;20(1):362.

26. Silber CG, Nasca TJ, Paskin DL, Eiger G, Robeson M, Veloski JJ. Do global rating forms enable program directors to assess the ACGME competencies? Academic medicine : journal of the Association of American Medical Colleges. 2004;79(6):549-56.

27. Golnik KC, Goldenhar LM, Gittinger JW, Jr., Lustbader JM. The Ophthalmic Clinical Evaluation Exercise (OCEX). Ophthalmology. 2004:111(7):1271-4

28. Golnik KC, Goldenhar L. The ophthalmic clinical evaluation exercise: reliability determination. Ophthalmology. 2005;112(10):1649-54.

29. Reisdorff EJ, Carlson DJ, Reeves M, Walker G, Hayes OW Reynolds B. Quantitative validation of a general competency composite assessment evaluation. Academic emergency medicine official journal of the Society for Academic Emergency Medicine. 2004;11(8):881-4.

30. Durning SJ, Pangaro LN, Lawrence LL, Waechter D, McManigle J, Jackson JL. The feasibility, reliability, and validity of a program director's (supervisor's) evaluation form for medical school graduates. Academic medicine : journal of the Association of American Medica Colleges. 2005;80(10):964-8.
31. Artino AR, Jr., Dong T, Cruess DF, Gilliland WR, Durning SJ. Development and initial validation of a program director's evaluation form for third-year residents. Military medicine. 2015;180(4 Suppl):104-8.

32. Kassam A, Donnon T, Rigby I. Validity and reliability of an in-training evaluation report to measure the CanMEDS roles in emergency medicine residents. Cjem. 2014;16(2):144-50.

33. Terry R, Hing W, Orr R, Milne N. Do coursework summative assessments predict clinical performance? A systematic review. BMC medical education. 2017;17(1):40.

34. van Zanten M, Boulet JR, Norcini JJ, McKinley D. Using a standardised patient assessment to measure professional attributes. Medical education. 2005;39(1):20-9.

35. Yang YY, Lee FY, Hsu HC, Lee WS, Chuang CL, Chang CC, et al. Validation of the behavior and concept based assessment of professionalism competence in postgraduate first-year residents. Journal of the Chinese Medical Association : JCMA. 2013;76(4):18694.

36. Ling LJ, Beeson MS. Milestones in emergency medicine. Journal of Acute Medicine. 2012;2(3):65-9.

37. Jefferies A, Simmons B, Tabak D, Mcllroy JH, Lee K-S, Roukema H, et al. Using an objective structured clinical examination (OSCE) to assess multiple physician competencies in postgraduate training. Medical teacher. 2007;29(2-3):183-91.

38. Ponton-Carss A, Hutchison C, Violato C. Assessment of communication, professionalism, and surgical skills in an objective structured performance-related examination (OSPRE): a psychometric study. The American Journal of Surgery. 2011;202(4):433-40.

39. Tetzlaff John E, Warltier David C. Assessment of Competency in Anesthesiology. Anesthesiology. 2007;106(4):812-25.

40. Yang YY, Lee FY, Hsu HC, Huang CC, Chen JW, Lee WS, et al. A core competence-based objective structured clinical examination (OSCE) in evaluation of clinical performance of postgraduate year-1 $\left(P G Y_{1}\right)$ residents. Journal of the Chinese Medical Association : JCMA. 2011;74(5):198-204.

41. Musick DW, McDowell SM, Clark N, Salcido R. Pilot study of a 360 degree assessment instrument for physical medicine \& rehabilitation residency programs. American journal of physical medicine \& rehabilitation. 2003;82(5):394-402.

42. Abadel FT, Hattab AS. Patients' assessment of professionalism and communication skills of medical graduates. BMC medical education. 2014;14(1):28.

43. Park YS, Riddle J, Tekian A. Validity evidence of resident competency ratings and the identification of problem residents. Medical education. 2014;48(6):614-22.

44. Brinkman WB, Geraghty SR, Lanphear BP, Khoury JC, Gonzalez del Rey JA, DeWitt TG, et al. Evaluation of resident communication skills and professionalism: a matter of perspective? Pediatrics. 2006;118(4):1371-9.

45. Jones CA, Watkins FS, Williams J, Lambros A, Callahan KE, Lawlor $\mathrm{J}$, et al. A 360-degree assessment of teaching effectiveness using a structured-videorecorded observed teaching exercise for faculty development. Medical Education Online. 2019;24(1):1596708.

46. Lockyer J. Multisource feedback in the assessment of physician competencies. The Journal of continuing education in the health professions. 2003;23(1):4-12.

47. Sullivan C, Arnold L. Assessment and Remediation in Programs of Teaching Professionalism. In: Cruess RL, Cruess SR, Steinert Y, editors. Teaching Medical Professionalism. Cambridge: Cambridge University Press; 2008. p. 124-49.

48. de Oliveira Filho GR, Dal Mago AJ, Garcia JHS, Goldschmidt R. An Instrument Designed for Faculty Supervision Evaluation by Anesthesia Residents and Its Psychometric Properties. Anesthesia \& Analgesia. 2008;107(4)

49. Dehon E, Robertson E, Barnard M, Gunalda J, Puskarich M. Development of a Clinical Teaching Evaluation and Feedback Tool for Faculty. West J Emerg Med. 2019;20(1):50-7.

50. Li H, Ding $N$, Zhang $Y$, Liu $Y$, Wen D. Assessing medical professionalism: A systematic review of instruments and their measurement properties. PloS one. 2017;12(5):e0177321-e 